\title{
Caesarean section in morbidly obese parturient: Technical difficulties \\ Das $\mathrm{T}^{1}$ iD , Saha $\mathrm{R}^{2}$ iD, Manandhar $\mathrm{R}^{3}$ iD
}

${ }^{1}$ Tanya Das, MD Resident; ${ }^{2}$ Rachana Saha, Professor; ${ }^{3}$ Rosina Manandhar, Lecturer; Department of Obstetrics and Gynaecology, Kathmandu Medical College Teaching Hospital, Sinamangal, Kathmandu, Nepal.

\begin{abstract}
Approximately one third of women of reproductive age group are obese. Obesity significantly increases caesarean section rate. Not only is obesity associated with unfavourable clinical outcomes for both mother and child also, performing caesarean sections in morbidly obese patients is a challenge for obstetricians, anaesthetists and the caregivers. In view of increased risks while performing Caesarean delivery in morbidly obese patient, this case report reviews the techniques and incisions used; the anaesthetic, logistical and practical challenges faced by the obstetricians while performing an emergency caesarean section in a women with BMI of $45.78 \mathrm{~kg} / \mathrm{m} 2$ who was also a diagnosed case of chronic hypertension with Grade I hypertensive retinopathy.
\end{abstract}

Key words: Caesarean section; Morbid obesity; Spinal anaesthesia.

\section{INTRODUCTION}

$\mathrm{O}$ besity is defined as excessive fat accumulation that may impair health with BMI greater than or equal to $30^{1}$.According to data published by World Health Organisation in 2018, the percentage of women with a body mass index (BMI) of $50 \mathrm{Kg} / \mathrm{m}^{2}$ or more has increased five-fold in 20 years, with $8 \%$ of them belonging to reproductive age group ${ }^{2}$.

Morbid obesity has a dramatic impact on pregnancy outcomes. It poses an increased risk of diabetes,

\section{Access this article online}

Website: www.jkmc.com.np

DOI: https://doi.org/10.3126/jkmc.v9i1.33545

\section{HOW TO CITE}

Das T, Saha R, Manandhar R. Caesarean section in morbidly obese parturient: Technical difficulties. J Kathmandu Med Coll. 2020;9(1):60-62.

\section{Address for correspondence}

Dr. Tanya Das

Resident, Department of Obstetrics and Gynaecology

Kathmandu Medical College Teaching Hospital

Sinamangal, Kathmandu, Nepal

E-mail: tanidas1030@gmail.com

Copyright ๔ 2020 Journal of Kathmandu Medical College (JKMC)

ISSN: 2019-1785 (Print), 2091-1793 (Online)

(7) (5) This work is licensed under a Creative Commons Attribution-Non Commercial 4.0 International License. hypertension, pre-eclampsia ,preterm delivery, and emergency caesarean section.

Performing Lower segment caesarean section(LSCS) in a morbidly obese parturient faces many technical difficulties which includes anaesthesia related complications, intra-operative and postoperative challenges ${ }^{3}$.

This is a case report of a morbidly obese patient undergoing caesarean section in a low resource setting and the difficulties that were encountered during the procedure and the postpartum period.

\section{CASE REPORT}

A 39 year Booked, Immunised, Primigravida presented to Kathmandu Medical College Teaching Hospital (KMCTH) at 38 weeks 2 days of gestation with complaints of decreased fetal movements for one day. She was a known case of chronic hypertension with Grade 1 hypertensive retinopathy. Her weight at the time of admission was 116 $\mathrm{kg}$ and height was $159 \mathrm{~cm}$. Her BMI was $45.78 \mathrm{~kg} / \mathrm{m} 2$. Her antenatal period was uneventful throughout.

On admission, her blood pressure was $150 / 100 \mathrm{~mm} \mathrm{Hg}$ (bilateral arms) and pitting pedal oedema was present. Her systemic examination revealed no abnormalities. Her baseline investigations were within normal limits. Her Non-Stress Test (NST) was done which was found to be of category III. 
An emergency caesarean section was planned in view of a non- reassuring NST with chronic hypertension in a morbidly obese patient. The anaesthetic team planned for spinal Anaesthesia in view of anticipated difficult intubation.

Patient was positioned for spinal anaesthesia but the landmark was difficult to identify due to oedema. A $139 \mathrm{~mm}$ length 27 gauge Quincke spinal needle was tried in L3-L4 space. Due to difficulty in positioning and thick fat layer, a second attempt was made in the L2-L3 space using Whitacre 27 gauge spinal needle by a senior anaesthetist within a duration of 50 minutes.

During the three hours duration of the surgery, the patient was positioned supine with left lateral tilt using a wedge. The surgeon needed double stairs for adequate visualisation of the operative field. Cephalad retraction of the panniculus was done using gauze piece and towel clips. A suprapannicular transverse incision was given. A Female Baby weighing $3.5 \mathrm{~kg}$ was delivered, with an Apgar score of 4,5 and 7at 1,5 and 10 minutes respectively. The subcutaneous fat layer was sutured and two subcutaneous drains were placed.

There were no anaesthetic complications intraoperatively or post-operatively. Patient was shifted to post-operative ward which required 6 personnel and a larger bed.

During her post-operative period, she was given low molecular weight heparin for thromboprophylaxis. She was also given antibiotic prophylaxis. The subcutaneous drain was removed on the $5^{\text {th }}$ post-operative day and sutures were removed on $14^{\text {th }}$ post-operative day. She was discharged on her $18^{\text {th }}$ post-operative day. Her baby had NICU stay of 17 days.

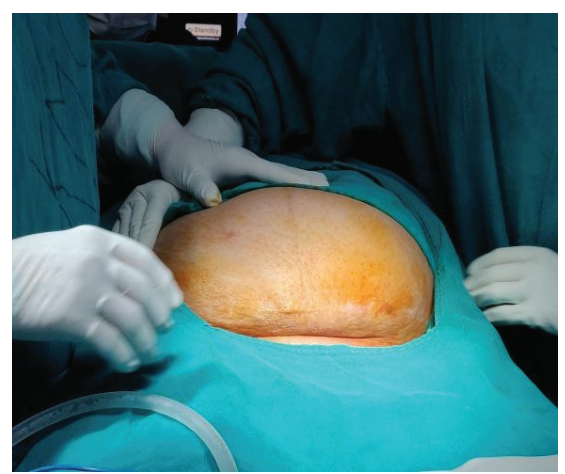

Figure 1: Pannus

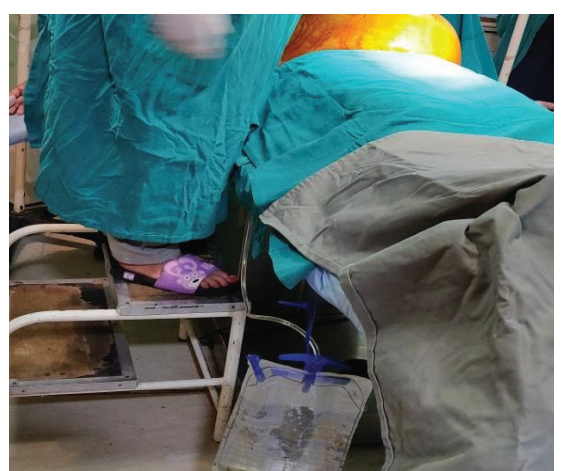

Figure 2: Surgeon on double stairs

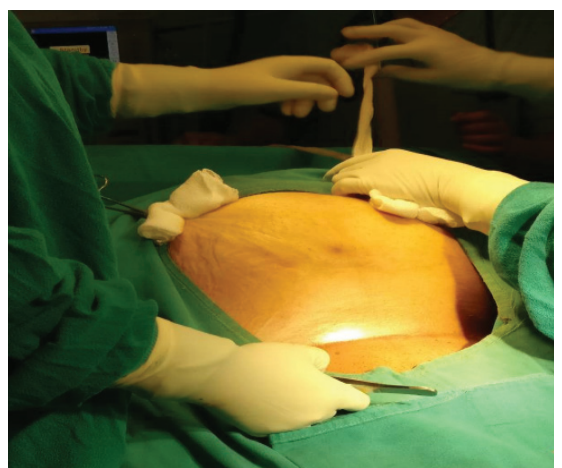

Figure 3: Cephalad retraction of panniculus
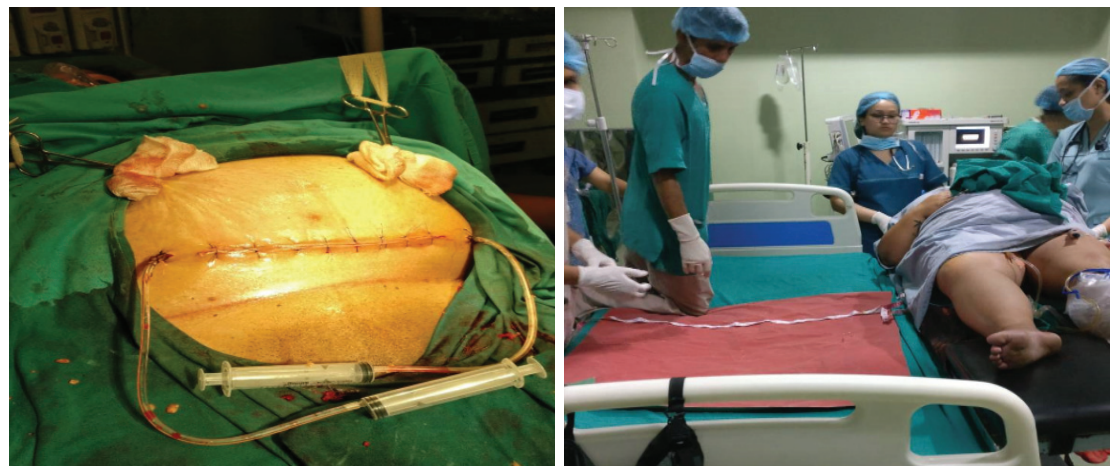

Figure 4: Placement of subcutaneous Figure 5: Shifting patient drains 


\section{DISCUSSION}

Likelihood of vaginal delivery decreases with increasing obesity $^{4}$. Spinal anaesthesia and epidural analgesia is difficult and often unsuccessful though combined spinal epidural (CSE) anaesthesia remains the anaesthesia of choice in obese patients ${ }^{5}$. Position of patient during caesarean section is supine with lateral tilt which is difficult to obtain in morbidly obese patient in a standard operating bed. Pfannenstiel incision poses a risk for infection due to large panniculus and difficulty is also encountered in obtaining adequate exposure using this incision. An alternative to pfannenstiel incision is suprapannicular incision which reduces the risk of infection ${ }^{5}$.Cephalad retraction of the panniculus in morbidly obese patients during caesarean section carries the risk of hypotension and respiratory difficulties ${ }^{6}$. Closure of subcutaneous layer is recommended but placement of drains still remains a topic of controversy ${ }^{4}$.

According to RCOG guidelines 2018, all maternity units should have a documented environmental risk assessment regarding the availability of facilities to care

\section{REFERENCES}

1. WHO. Obesity: Preventing and managing the global epidemic. Report of a WHO Consultation. WHO Technical Report Series 894; Geneva, Switzerland: 2000 [Full Text].

2. World Health Organisation. Obesity and overweight. Geneva:WHO; April 2020. [Full Text]

3. Machado LSM. Cesarean Section in Morbidly Obese Parturients: Practical Implications and Complications. N Am J Med Sci. 2012 Jan; 4(1): 13-8. [Full Text]

4. Antonakou A, Papoutsis D, Tzavara C. Maternal obesity and its association with the mode of delivery and the neonatal outcome in induced labour: Implications for midwifery practice. European Journal of Midwifery. 2018;2(April). [Full Text] for women with $\mathrm{BMI}>30 \mathrm{~kg} / \mathrm{m} 2$. The risk assessment should address the following issues: circulation space, accessibility including doorway widths and thresholds, safe working loads of equipment and floors, appropriate theatre gowns, equipment storage, transportation, and staffing levels and availability of specific equipment. ${ }^{7}$ Increased incidences of wound infection and venous thromboembolism is seen inmorbidly obese women hence, prophylaxis is to be given ${ }^{4}$.

\section{CONCLUSION}

The prevalence of obesity is increasing, and it is associated with significant comorbidities, difficulty in performing a Caesarean section being one among them. Hence, we need to address this situation which includes preoperative counselling of patients, access to adequate equipment, transportation, staffing and newer operative techniques as well as post operative care and complications.

Conflict of interest: None

Source(s) of support: None
5. Loubert C, Fernando R. Cesarean delivery in the obese parturient:Anesthetic considerations. Sage journals on women's health. 2011 Mar;7(2):163-79. [DOI]

6. Said HM, Childress KM, Miller C, McCormick K, Hostetter SE, Flick AA. Low Versus High Transverse Skin Incisions for Obese Patients Undergoing Cesarean Delivery [14K]. Obstetrics \&Gynecology. 2016 May 1;127:82S. [PubMed]

7. Denison FC, Aedla NR, Keag O, Hor K, Reynolds RM, Milne A, Diamond .Royal College of Obstetricians and Gynaecologists. Care of Women with Obesity in Pregnancy: Greentop Guideline No. 72. BJOG: An International Journal of Obstetrics \& Gynaecology. 2019 Feb;126(3):e62-106. [DOI] 